\title{
Management Guidelines For Universal Quality Challenges Across The Focus Group Research Process
}

Busani Dube, University of Johannesburg, South Africa

Mornay Roberts-Lombard, University of Johannesburg, South Africa

Estelle van Tonder, North-West University, South Africa

\begin{abstract}
The general misuse of the focus group method may have quality implications for decision-making processes of organisations across the industry spectrum and for further research. To assist in addressing the problem, this study sought to uncover the challenges that impede the quality of the focus group research process and develop a set of management guidelines for redress by stakeholder organisations. The population of interest for the study consisted of all South African organisations that supply or use marketing research information generated through the use of focus groups. The empirical part of the research study comprised of both a qualitative and a quantitative phase. A CATI approach was used for data collection and the research method employed for the study was a questionnaire survey. An ordinal, 5-point Likert scale was used to measure the responses in the study. The Pearson chi-square test was also employed to compare the research quality perceptions of research suppliers and users within the focus group process. The findings revealed numerous instances of similarities between research suppliers and users regarding their views on focus group research and the quality challenges thereof. Following the research findings, a number of management guidelines were developed that research practitioners could employ to improve the standard of focus group research in South Africa.
\end{abstract}

Keywords: Focus Groups; Challenges; Quality Guidelines; Research Suppliers; Research Users

\section{INTRODUCTION}

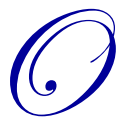

ver the past two decades the focus group research method has become more popular among researchers in the international marketing arena. In fact, many practitioners regard the focus group research technique as being synonymous with qualitative research and particularly favour this approach, because of its cost advantage above the more expensive quantitative research options. (Prakash, 2013; Kent, 2007, p. 85; Malhotra, 2007, p. 146; Stokes \& Bergin, 2006, p. 26-37).

The focus group research method entails a group interview approach where group interaction, dynamics and synergy lead to joint construction of meaning, and thus valuable consumer insights may be obtained on a given topic (Bryman \& Belle, 2007, p. 728; Kress \& Shoffner, 2007, p. 189-195; Welman, Kruger \& Mitchell, 2005, p. 201). The group interaction facilitates idea exchange and evaluation (Raby, 2010, pp. 1-15; Baruah \& Paulus, 2009, pp. 29-56) and the creative insights result from the interplay among respondents and multiple views and perspectives shared, which stimulate thought among focus group members (Zikmund \& Babin, 2013, p. 108). Furthermore, the multivocality of focus group interaction and discussions provides a valuable breadth of information on a topic of discussion (Stokes \& Bergin, 2006, pp. 26-37) and the synergy created allows the group to exceed the benefit of merely adding up contributions of individuals working independently (Baruah \& Paulus, 2009, pp. 29-56; Hartman, 2004, pp. 402-410). Because of these advantages, the focus group research method has been defined as an efficient, practical and applied method of gathering qualitative research information (Kress \& Shoffner, 2007, pp. 189-195). 
Researchers following qualitative research methods in general and focus groups in particular, however, must apply key quality guidelines in order to enhance scientific research practice. More particularly, the methodological application ought to measure up to best practice in marketing research because the quality of research depends on the appropriateness and accurate application of the chosen method (Mrosovsky, 2006, pp. 790791). Practitioners across the globe and also in South Africa must adhere to these principles in order to protect the integrity of the marketing research industry.

To assist South African marketing researchers in this regard, the South African Marketing Research Association, in its capacity as a regulatory body for marketing practitioners, has designed a code of conduct in an attempt to provide more guidance to marketing researchers on research ethics, policies and rules (SAMRA, 2009, pp. 1-3). However, within their framework there still remains a lack of specific guidelines on the disciplined conduct of qualitative marketing research.

These guidelines are imperative as evidence exists in the literature review which suggests that the process of conducting focus group research in South Africa may not be deemed efficient or well organised. To a large extent, the challenges relate to the misconducts or mismanagement of the focus group method by research supplier and user organisations alike (Martin, 2006, pp. 2-4; Green \& Green, 2005, pp. 1-9). The practices then lead to dire consequences for user organisations across industries. Unsuspecting research users paid for and applied the defective research to inform their decision-making processes, thereby risking failure in the face of market uncertainty.

Consequently, to protect the integrity of the marketing research industry in South Africa, an understanding of the universal challenges impacting on the quality of focus group research as well as guidelines that could be employed to assist in improving the standard of focus groups research in South Africa, is without a doubt warranted. Due to the popularity of the focus group method within the South Africa research environment, it is imperative to propose guidelines for practitioners on best practices that will assist them in executing their focus group studies in a more scientific manner.

It was the aim of this article to address the abovementioned requirements.

\section{RESEARCH PROBLEM}

Evidence exists in the literature reviewed, which suggests that the process of conducting focus group research in South Africa may not be deemed efficient or well organised. A lack of clear guidelines that could assist in improving the standard of focus group research was identified as a major quality challenge in South Africa. As a result, the general misuse of the focus group method may have quality implications for the decision-making processes of organisations across the industry spectrum and for further research. To protect the integrity of the marketing research industry in this country, it is imperative for a research study to be conducted that will seek to uncover the challenges that impede the quality of focus group research and develop a set of guidelines for redress by stakeholder organisations.

\section{OBJECTIVES}

Emanating from the research problem, the primary objective of the research study conducted for this article was to obtain an understanding of the universal challenges impacting on the quality of focus group research as well as to establish management guidelines that could be employed to assist in improving the standard of focus groups research in South Africa. 

objective:

The following secondary research objectives were formulated to assist in addressing the primary research

- $\quad$ Conduct a literature review to identify challenges that impact quality across the focus group research process and that will assist in formulating a discussion guide for the in-depth interviews to be facilitated.

- $\quad$ Conduct qualitative in-depth interviews with research suppliers and users in South Africa to obtain more insight into their perceptions of research quality problems within the focus group process.

- $\quad$ Based on the findings of the qualitative interviews, conduct quantitative interviews on a larger scale with research suppliers and users in South Africa to verify their perceptions on challenges that impact quality across the focus group research process.

- $\quad$ Compare the research quality perceptions of research suppliers and users within the focus group process.

\section{RESEARCH HYPOTHESIS}

The following research hypothesis was formulated to assist in addressing the fourth secondary research objective of the study:

HA $^{1}$ : There is a significant association between the perceptions of research suppliers and research users with regard to the quality challenges experienced across the focus group research process.

\section{THEORETICAL BACKGROUND}

This section commences with an overview of the importance of the South African marketing research industry, the purpose of focus group research within the marketing research environment, as well as a discussion of categories of focus group research. To assist in addressing the first secondary research objective formulated for the study, the latter part of the theoretical background is devoted to identify challenges that impact quality across the focus group research process and that will assist in formulating a discussion guide for the in-depth interviews to be facilitated.

\section{The Importance Of The South African Marketing Research Industry}

The South African marketing research industry provides an important platform for the practice of marketing research and is viewed as a growth industry within the international marketing research setting (Falala, 2003 , pp. 2-4). In essence, the importance of the South African marketing research industry stems from its direct contribution of marketing research expertise, which facilitates informed, evidence-, based marketing decisionmaking that helps organisations achieve desired business outcomes (Anthony \& Austin, 2008, pp. 287-293). Supplementary to the role of the marketing research function, there is also evidence of the important role played by the marketing research industry in the South African economy (Victor, 2009; Falala, 2003, pp. 2-4; Smith, 2003, pp. 3-4). As a developing industry, both in size and revenue within an emerging economy, South Africa presents opportunities for growth in many sectors across the industry spectrum. The South African research industry forms part of the international marketing research industry that has shown a turnover of $\$ 40.287$ million in 2013and has experienced an annual increase of 2.8\%. (ESOMAR, 2014, p. 6). The South African research industry is also regarded as the largest research market on the African continent (Cleveland \& Delorie, 2010).

\section{The Purpose Of Focus Groups Within The Marketing Research Environment}

Focus groups were conceived as an alternative method to the one-on-one approach in social sciences (Simon \& Mosavel, 2008, pp. 63-81), an area of scientific inquiry that embodies marketing research. Focus group research is widely described in the literature across research fields, including marketing research as a qualitative research method. Evidently, stemming from the reinforced definition of focus groups, Zikmund and Babin (2013, p. 108), Kress and Shoffner (2007, pp. 189-195), Stokes and Bergin (2006, pp. 26-37), and Welman et al. (2005, p. 201) qualify the focus group research method as not only a qualitative, but also a very useful marketing research method. Malhotra (2010, p. 173) confirms and qualifies focus groups as the most important qualitative research method used in marketing research. 
Fundamentally, the defining purpose of focus groups stems from its collectivist nature, concentration on the group interaction, and the expression of different perspectives. Essentially, as a data gathering method, focus groups serve to generate qualitative research data from which meaningful insights may be deduced for decision-making purposes of business organisations. The ability of focus groups as an efficient and practical method is central to their purpose in revealing consensus views, and generates rich data as they allow participants to challenge one another's views and enable views to be reformulated through the exchanges (Ashton, 2009, pp. 221-232; Malhotra, 2010, p. 169).

\section{Categories Of Focus Group Research}

Focus groups can be organised into three main categories namely, exploratory, clinical and experiencing focus groups. Exploratory focus groups are often used at the exploratory phase of the marketing research process, to obtain a better understanding of the research problem (Burns \& Bush, 2014, p. 103; University of WisconsinMadison, 1999, p. 4). Clinical focus groups entails to probe the respondents in order uncover their true motivations and feelings that are hidden at a subconscious level. With respect to experiencing focus groups, the researcher is subjected to the emotional framework in which a product for example, is being used, and thus obtains a better understanding of what the consumer experiences (Aaker et al., 2004, pp. 197-198). In addition, the design of the different types of categories, focus groups can either be conducted online or in a traditional manner. Online focus groups are less expensive, can be conducted anywhere in the world and the results are available immediately. Traditional focus groups are conducted in one location, are more expensive and transcripts will take longer to finalise (Malhotra, 2010, p. 184).

\section{Challenges Impacting Quality Across The Focus Group Research Process}

A further literature investigation revealed a number of challenges that can be experienced across the focus group research process and which the researchers had to incorporate into the in-depth interview discussion guide.

\section{General Practitioner Incompetence}

Practitioner triangulation such as the regular back-checking of questionnaires or discussion guides are not performed due to the fact that researchers are required to complete studies within short time frames (Green \& Green, 2005, pp. 1-9). Respondent time spans are further generally too short to conduct a recruitment process. Besides, there are not many focus group venues in South Africa and the few available are often fully booked, resulting in focus group respondents having to travel long distances to participate in the survey (Green \& Green, 2005).

\section{Questionable Research Skills}

Focus group research skills of some research suppliers are questionable, and may lead to industry misuse of the method. Some research suppliers tend to 'blindly and hurriedly' use research methods or tools without much consideration and scrutiny (Kolb, 2005, pp. 2-4), as the focus is on profit making (Falala, 2003, pp. 2-4). Apart from that, South African research suppliers lack the necessary skills to design, formulate and execute methodology strategies, which results in problems when it comes to scientific application of the focus group, let alone research quality standards (Maree \& Wagner, 2007, p. 122; Green \& Green, 2005, pp. 1-9).

\section{Lack Of Enforcement Of Industry Regulations}

Lack of enforcement of industry practice regulations to ensure compliance may be a contributing factor to the misuse of the focus group method in South Africa. Monitoring or supervision are essential to ensure the integrity of the research studies, focus groups or otherwise, as advocated by Ervin and Cowell (2004, pp. 183-190). However, there is insufficient evidence to suggest that effective quality monitoring mechanisms within the South African marketing research practice exist or are enforced. For this reason, deliberate disregard for existing regulations may be possible. Another constraining factor is that regulations can only be enforced on researchers who are registered and monitored members of the industry regulatory body, which is merely a quarter of the research suppliers in South Africa (Vorster, 2008, p. 1). 


\section{Disregard For Research Service Contracts}

Green and Green (2005, pp. 1-9) assert that focus group industry service providers, such as recruiters, for example, might not receive remuneration for services provided, if the respondents fails to turn up for the interview. At times, respondents who are not suitable to participate in the study are also asked to leave the venue and as a result the recruiter will not receive any remuneration, not only for the incorrect recruit, but also not for the rest of the group. There are further instances when an unsuitable respondent will be requested to stay on to avoid loss of income for the recruiter and other parties involved.

\section{Ignorance On How The Industry Operates}

General ignorance on how the industry operates, particularly on the part of some research user organisations, is evident in the local industry literature reviewed, and this may exacerbate issues of malpractice in the marketing research industry. Maritz (2012, p. 34) adds that low levels of skills, experience and education in the practice compromise quality of research. Research users often request and pay for flawed research studies at face value, purely because they do not have the necessary knowledge about and therefore risk business failure. Apart from that, research user organisations do not understand the difficulties in recruiting for a focus group, including the time it takes, effort required, frustrations recruiters encounter, and costs among other things. The fact that research suppliers and users further are not all in agreement on whether recruiters should be viewed as angels that do not cheat or cheating devils, could be interpreted as evidence of ignorance about what is going on beneath their noses (Maree \& Wagner, 2007, pp. 121-134; Green \& Green, 2005, pp. 1-9; Green, 2003, pp. 2-4).

\section{METHODOLOGY}

This section focuses on the research methodology that was followed to conduct the empirical investigation, including a discussion of the research population and sample frame, the sample size and selection criteria used, the data collection and research instrument followed, as well as the data analysis procedures that were employed.

To meet the second and third secondary research objectives of this article, the field study was conducted in two phases. In the first phase of the field study, qualitative in-depth interviews with research suppliers and users in South Africa were performed to obtain more insight into the problems that were identified in the literature review as well as the respondents' perceptions of research quality problems, within the focus group process. The second phase of the field study then focussed on quantitative interviews on a larger scale with research suppliers and users in South Africa to verify their perceptions on challenges that impact quality across the focus group research process.

\section{Research Population And Sample Frame}

The population of interest for the study consisted of all South African organisations that supply or use marketing research information generated through the use of focus groups. Research suppliers are specialist providers of marketing information and research users purchase and use the marketing information for decisionmaking purposes. The rationale for the use of research suppliers and users was not only to achieve a balance in terms of representation of both research supplier and user organisations in the sample, but also to obtain perspectives from the two sides. A sample frame of over 250 research suppliers and 950 active research user organisations, both registered and unregistered with SAMRA (Southern African Marketing Research Association), was used (SAMRA, 2010, pp. 77-99).

\section{Sample Size}

A sample can be defined as a portion of a larger population (Zikmund \& Babin, 2013, p. 312). In the first phase of the field study, namely the qualitative part, the sample consisted of two categories, that is, one for the research suppliers $(n=8)$ and the other for research user organisations $(n=10)$. Taking into consideration that it was the intention of the researchers to follow an exploratory and qualitative approach to investigate the problems identified in the literature review in more depth, the homogenous nature of the sample, and also the subsequent 
possibility of interviewing a saturated sample that will make no new contribution to the theory, a sample size of 18 respondents was deemed appropriate for the purpose of this study.

In the second part of the field study, the quantitative phase, a sample size of 600 potential respondents was considered large and adequate for conducting quantitative interviews on a larger scale with research suppliers and users in South Africa to verify their perceptions on challenges that impact quality across the focus group research process. The use of a large sample was also justified on the basis of the value of the information and the accuracy level desired. The sample units or respondents were selected from identified business organisations of both research suppliers and users. Names of the focus group research user organisations were available on the SAMRA database, while some were gleaned from the websites of some research supplier organisations within the South African marketing research industry, where they were posted for advertising purposes. Whereas $244(40.7 \%)$ of the individual respondents were drawn from one hundred and eighty nine research supplier organisations, 356 (59.3\%) participated as representatives of two hundred and twenty six research user organisations.

\section{Sample Selection Criteria}

A non-probability judgement sample was drawn for the qualitative part of the field study. Malhotra (2010, p. 379) defines a judgemental sampling as "a form of convenience sampling in which the population elements are selected based on the judgement of the researcher". In this regard, respondents from organisations currently active within the South African marketing research industry were considered. Only respondents from research supplier organisations that use focus groups, and research user organisations that have experienced or used research results derived from the use of focus groups, were used. An informal screening procedure based on inquiries and checks on individuals' background was conducted.

A similar type of approach was also followed in the quantitative part of the field study. Given the specialised nature of focus group research in South Africa and in terms of the design of this study, only appropriately qualified respondents, that is, those with the knowledge and experience on focus group research from both suppliers and users were considered. In terms of the sample selection criteria, each of the focus group research supplier and user organisations featured in the sample frame of the study was considered a research cluster, and was thus coded accordingly for sampling purposes. Zikmund and Babin (2013, p. 329) define cluster sampling as the division of the population into subgroups, labelled clusters, and a random sample of the clusters is chosen for the purpose of the study. Cluster sampling was preferred because it is said to be cost effective, as it improves the sampling efficiency by decreasing the cost at a faster rate than accuracy. Reminiscent of probability sampling method, the sample selection criteria entailed a systematic random selection of the clustered organisations, which involved the selection of every second cluster organisation from the sample frame that was randomly ordered as guided by Malhotra (2010, p. 383). With each organisation targeted constituting a cluster, all elements or respondents with knowledge and experience on focus group research that met the selection criteria within were identified, then selected to determine the research sample.

\section{Data Collection And Research Instrument}

In the qualitative phase of the field study, in-depth interviews were conducted for data collection purposes in the Gauteng Province in South Africa. This region was selected based on the fact that according to Victor (2009), a heavy concentration of the research suppliers is based within the Gauteng Province, perhaps owing to its status as the country's commercial research hub. A small number of research suppliers are based in Cape Town and KwaZulu-Natal, and one or none in other regions of the country (Victor, 2009). Furthermore, the in-depth research method was deemed suited for this study because it offers unhindered conversations in a social sense. The in-depth interview method generates data in an unconstrained but vivid atmosphere (DeRosia \& Christensen, 2009, pp. 1535; Malhotra, 2010, p. 188). The identity of respondents was treated as confidential, given the competitive rivalry within the South African marketing research industry. Respondents were manually coded 1, 2, 3, etcetera, for similar reasons. A discussion guide was used as the data collection instrument, essentially to obtain pertinent opinions and views of representatives of both research supplier and user organisations. The discussion guide contained structured topics determined on the basis of issues arising from the literature reviewed. The discussion guide was deemed appropriate for purposes of the study because it allows for flexibility with respect to the use of in-depth interviews 
$(\mathrm{n}=18)$, where probing questions may be asked to get deeper and more elaborate explanations from the interview discussion (Zikmund \& Babin, 2013, p. 112). The discussion guide was pilot-tested on a total of 4 respondents prior to the study being conducted, in order to refine the research topics.

In the quantitative phase of the field study, the research method employed for the study was a questionnaire survey. The questionnaire was developed on the basis of the findings of the preceding qualitative study and was deemed appropriate as a formalised schedule for collecting information from respondents. An ordinal, 5-point Likert scale was used to measure the responses in the study. The 5-point Likert scale was preferred because of the few response options it offered, and thus proved easier to administer than when a broader scale would have been used. Apart from that, the rationale for using the Likert scale was to generate categorical data, which was appropriate for conducting tests for establishing frequency distributions, levels of agreement or disagreement and significance of associations or independence between variables among other things (Pallant, 2010, p. 118). The questionnaire survey was conducted using the Computer Assisted Telephone Survey (CATI) method. Essentially, the CATI approach entailed the interviewer taking the respondent through the questionnaire question by question, leaving no option for no responses nor refusals, especially as wide response options were given and respondents were guided through the questions. On this basis, CATI eliminated the potential for a low response rate, and the planned sample size of 600 respondents was thus achieved. For these reasons, neither missing values nor incomplete responses were realised in the data collected. Also, CATI offered increased speed, accuracy and instant recording of the data while being collected. Increased efficiencies of CATI in turn facilitated easier data organisation, processing and conducting analysis thereof, apart from revealing subgroup differences on the data collected that both Malhotra (2010, p. 213) and Burns and Bush (2014, p. 228) emphasise. In order to identify and eliminate potential problems (Malhotra, 2010, p. 354), the questionnaire was pretested on a small sample of 10 respondents, 5 drawn from research supplier organisations and another 5 from research user organisations.

\section{Data Processing And Analysis}

In the first part of the field study, a qualitative data processing and analysis approach was employed, and entailed data cleaning and preparation for quality purposes. This process involved general editing by checking the data for consistency, correctness and completeness (Malhotra, 2010, p. 453). The data was manually coded using number codes, and data that fell outside the coding procedure and any ambiguities identified were thus cleared to ensure the reliability and accuracy of the data analysis process, as advocated by Segal, Hershberger and Osmonbekov (2009, pp. 70-82) and Famili (2005, pp. 417-418). A qualitative content analysis was conducted on transcripts produced for the identification and categorisation of themes, trends, content and issues on quality challenges arising from the in-depth interviews (Stavros \& Westberg, 2009, pp. 307-320; Ratcliff, 2008, pp. 116133). As advocated by Keegan (2009, pp. 234-248) scientific rigour, reflection, analysis and interpretation of qualitative data were vigorously pursued.

In the second phase of the field study, the statistical data collected was also subjected to an initial data preparation process for quality purposes (Malhotra, 2010, p. 453). Once the data had been cleaned and was deemed free of errors as advocated by Pallant (2010, p. 53), the descriptive statistical analysis and different tests were conducted on the data set.

Statistical analysis and processing of the data collected entailed the use of the Statistical Package for Social Sciences (SPSS 18.0) programme.

\section{Validity Of Data Collected}

In the first part of the field study, the face validity technique, including preliminary discussions with major players and the piloting of the study, were followed as a scientifically rigorous procedure to ensure the fieldwork would be validated.

In the second part of the field study, the construct measured was developed from the literature reviewed as an independent and non-homogeneous item. For this reason, testing the measurement scale for reliability in terms of 
establishing the Cronbach's alpha values and internal consistency was not appropriate. In particular, because the research items under the construct measured were varied and unrelated (Pallant, 2010, p. 97).

Subsequently, given the absence of complete internal consistency due to the grounded theory approach used in developing the construct measured, the 5-point Likert scale employed was validated based on evidence of face or content validity. As Zikmund and Babin (2013, p. 258) posit, face validity is present when a scale's content logically appears to reflect what was intended to be measured. Also, face or content validity of the scale was enhanced on the strength of validation of the research items listed thereon, which were confirmed through the qualitative study prior to inclusion on the research instrument that was later pretested. This way, as Malhotra (2010, p. 320) asserts, representativeness of the content of the scale for the problem at hand, which was achieved.

\section{EMPIRICAL FINDINGS}

The qualitative phase of the field study confirmed and corroborated some of the focus group quality challenges that were identified in the literature review, but a number of additional problems were also reported. As such, after careful evaluation, the following nine specific challenges were listed and further tested in the quantitative phase of the field study:

- $\quad$ Incorrect use of focus groups is due to ignorance of scientific principles.

- $\quad$ Tight project timelines make it difficult to follow scientific guidelines in focus group research.

- $\quad$ Conducting focus group research requires the scientific application of the method.

- $\quad$ Scientific guidelines on the application of focus groups are required in South Africa.

- $\quad$ Taking shortcuts during the research process happens when the budget size is small.

- $\quad$ Challenges encountered on focus group projects are not considered when setting the budgets.

- $\quad$ Failure of focus group research projects occurs due to budget limitations.

- $\quad$ Poor quality findings result from malpractices by participants within the focus groups.

- Lack of participants' integrity compromises the quality of focus group research.

To meet the third and fourth secondary research objectives of this article and address the research hypothesis that was formulated, the remaining part of this section is subsequently devoted to an analysis of the quantitative results. Frequency statistics will be used to verify the perceptions of the respondents regarding the nine possible challenges that can have an impact on the quality across focus group research. In addition, the Pearson chisquare test will also be employed to compare the research quality perceptions of research suppliers and users within the focus group process. The research study at hand relied on a 95\% confidence interval. A p-value of less than 0.05 would subsequently indicate that there is a significant association between the means of the two variables, concerning the Pearson chi-square test. 


\section{Analysis Of Quantitative Results}

\section{Frequency Of Distributions}

The frequency of distributions of the quantitative results is displayed in Table 1.1.

Table 1.1: Frequency Of Distribution Of Quantitative Results

\begin{tabular}{|c|c|c|c|}
\hline Statements & Agree \% & Disagree \% & Neutral \% \\
\hline 1. Incorrect use of focus groups is due to ignorance of scientific principles. & 63.1 & 17 & 17.9 \\
\hline $\begin{array}{l}\text { 2. Tight project timelines make it difficult to follow scientific guidelines in } \\
\text { focus group research. }\end{array}$ & 54 & 31.3 & 14.7 \\
\hline $\begin{array}{l}\text { 3. Conducting focus group research requires scientific application of the } \\
\text { method. }\end{array}$ & 65 & 15.8 & 19.2 \\
\hline $\begin{array}{l}\text { 4. Scientific guidelines on the application of focus groups are required in } \\
\text { South Africa. }\end{array}$ & 61 & 15.8 & 23.2 \\
\hline $\begin{array}{l}\text { 5. Taking shortcuts during the research process happens when the budget } \\
\text { size is small. }\end{array}$ & 68.5 & 22.5 & 9 \\
\hline $\begin{array}{l}\text { 6. Challenges encountered during focus group projects are not considered } \\
\text { when setting the budgets. }\end{array}$ & 59 & 29.3 & 11.7 \\
\hline 7. Failure of focus group research projects occurs due to budget limitations. & 48.2 & 34 & 17.8 \\
\hline $\begin{array}{l}\text { 8. Poor quality findings result from malpractices by participants within the } \\
\text { focus groups. }\end{array}$ & 64 & 17.7 & 17.3 \\
\hline $\begin{array}{l}\text { 9. Lack of participants' integrity compromises the quality of focus group } \\
\text { research. }\end{array}$ & 91.7 & 3.5 & 4.8 \\
\hline
\end{tabular}

From Table 1.1 it is clear that the majority of the respondents who participated in the study were in agreement with all nine statements that were made regarding the quality challenges experienced in focus group research. The respondents agreed most with the statement that a lack of participants' integrity compromises the quality of focus group research $(91.7 \%)$. The respondents least agreed with the statement that failure of focus group research projects occurs due to budget limitations (48.2\%). 


\section{Comparison Between The Perceptions Of Research Suppliers And Research Users}

The results obtained from the Pearson chi-square statistics applied are displayed in Table 1.2.

Table 1.2: Statistical Results From Quantitative Study

\begin{tabular}{|c|c|c|c|c|c|c|c|c|c|}
\hline Statements & $\begin{array}{c}\text { Research } \\
\text { Suppliers (N) }\end{array}$ & $\begin{array}{l}\text { Research } \\
\text { Users (N) }\end{array}$ & $\begin{array}{c}\text { Total } \\
(\mathbf{N})\end{array}$ & $\begin{array}{l}\text { Total } \\
\text { Mean }\end{array}$ & \multicolumn{5}{|c|}{ Pearson Chi-Square Statistics } \\
\hline & & & & & $\begin{array}{l}\text { Suppliers } \\
\text { Mean }\end{array}$ & $\begin{array}{l}\text { Users } \\
\text { Mean }\end{array}$ & Value & df & P-Value \\
\hline $\begin{array}{l}\text { 1. Incorrect use of focus groups is due } \\
\text { to ignorance of scientific principles. }\end{array}$ & 244 & 356 & 600 & 3.56 & 3.52 & 3.58 & 9.804 & 4 & 0.044 \\
\hline $\begin{array}{l}\text { 2. Tight project timelines make it } \\
\text { difficult to follow scientific guidelines } \\
\text { in focus group research. }\end{array}$ & 244 & 356 & 600 & 3.12 & 3.27 & 3.24 & 15.274 & 4 & 0.004 \\
\hline $\begin{array}{l}\text { 3. Conducting focus group research } \\
\text { requires scientific application of the } \\
\text { method. }\end{array}$ & 244 & 356 & 600 & 3.55 & 3.45 & 3.62 & 21.928 & 4 & 0.000 \\
\hline $\begin{array}{l}\text { 4. Scientific guidelines on the } \\
\text { application of focus groups are required } \\
\text { in South Africa. }\end{array}$ & 244 & 356 & 600 & 3.53 & 3.39 & 3.62 & 15.106 & 4 & 0.004 \\
\hline $\begin{array}{l}\text { 5. Taking shortcuts during the research } \\
\text { process happens when the budget size is } \\
\text { small. }\end{array}$ & 244 & 356 & 600 & 3.58 & 3.59 & 3.58 & 13.306 & 4 & 0.010 \\
\hline $\begin{array}{l}\text { 6. Challenges encountered during focus } \\
\text { group projects are not considered when } \\
\text { setting the budgets. }\end{array}$ & 244 & 356 & 600 & 3.35 & 3.38 & 3.33 & 20.325 & 4 & 0.000 \\
\hline $\begin{array}{l}\text { 7. Failure of focus group research } \\
\text { projects occurs due to budget } \\
\text { limitations. }\end{array}$ & 244 & 356 & 600 & 3.17 & 3.14 & 3.19 & 4.376 & 4 & 0.358 \\
\hline $\begin{array}{l}\text { 8. Poor quality findings result from } \\
\text { malpractices by participants within the } \\
\text { focus groups. }\end{array}$ & 244 & 356 & 600 & 3.53 & 4.19 & 4.14 & 8.404 & 4 & 0.078 \\
\hline $\begin{array}{l}\text { 9. Lack of participants' integrity } \\
\text { compromises the quality of focus group } \\
\text { research. }\end{array}$ & 244 & 356 & 600 & 4.17 & 3.46 & 4.75 & 12.372 & 4 & 0.015 \\
\hline
\end{tabular}

According to Table 1.2 the p-value of the Pearson chi-square statistic is below 0.05 for all statements, except for statements seven and eight. Subsequently, it seems that there is a significant association between the means of research suppliers and users with regard to all statements, except for statements seven and eight.

On this basis it is then possible to accept the research hypothesis that was formulated for the study namely, that there is a significant association between the perceptions of research suppliers and research users with regard to the quality challenges experienced across the focus group research process. 
Table 1.3.

Cramer's V was conducted to determine the strength of each association. The results are displayed in

Table 1.3: Strength Of Association

\begin{tabular}{|l|c|c|}
\hline Statements & Cramer's V Value & Level Of Strength \\
\hline 1. Incorrect use of focus groups is due to ignorance of scientific principles. & 0.128 & Small effect \\
\hline $\begin{array}{l}\text { 2. Tight project timelines make it difficult to follow scientific guidelines in } \\
\text { focus group research. }\end{array}$ & 0.160 & Small effect \\
\hline $\begin{array}{l}\text { 3. Conducting focus group research requires scientific application of the } \\
\text { method. }\end{array}$ & 0.191 & Small effect \\
\hline $\begin{array}{l}\text { 4. Scientific guidelines on the application of focus groups are required in } \\
\text { South Africa. }\end{array}$ & 0.159 & Small effect \\
\hline $\begin{array}{l}\text { 5. Taking shortcuts during the research process happens when the budget } \\
\text { size is small. }\end{array}$ & 0.149 & Small effect \\
\hline $\begin{array}{l}\text { 6. Challenges encountered during focus group projects are not considered } \\
\text { when setting the budgets. }\end{array}$ & 0.184 & Small effect \\
\hline 7. Failure of focus group research projects occurs due to budget limitations. & - & Small effect \\
\hline $\begin{array}{l}\text { 8. Poor quality findings result from malpractices by participants within the } \\
\text { focus groups. }\end{array}$ & - & Small effect \\
\hline $\begin{array}{l}\text { 9. Lack of participants' integrity compromises the quality of focus group } \\
\text { research. }\end{array}$ & 0.144 & \\
\hline
\end{tabular}

Based on Table 1.3, it seems that all values fell between the range of 0.1 and 0.3 , indicating that the relationships identified are not very strong.

Finally, following the discussion in this section it can be concluded that the comparative analysis revealed collective similarities of perceptions on quality challenges relating to all nine statements measured, which were largely in the affirmative.

The implications of these findings then are that both research suppliers and research users have similar views concerning the nine statements that were made regarding quality challenges across the focus group research process, and that the managerial implications resulting from the research findings discussed in the next section, could subsequently be of value to both research suppliers and research users with regard to improving the standard of focus group research in South Africa.

\section{MANAGERIAL IMPLICATIONS}

To address the last secondary research objective formulated for this study, this section highlights a number of managerial implications that would need to be considered to ensure that quality research practices are employed across the focus group research process. The managerial implications are directly linked to the nine statements that were assessed in the quantitative study and are subsequently presented in the same order:

Firstly, both research suppliers and users shared significantly similar perceptions with respect to the major quality considerations stipulated for mitigating challenges relating to scientific application or lack thereof, of the focus group research method. Subsequently, it is recommended that both research suppliers and users must be educated on the scientific principles of the focus group method to counter the inherent challenge of incorrect use of the method.

Secondly, reasonable and flexible time frames must be stipulated and agreed to between stakeholder parties involved for focus group projects in order to eliminate instances of rushed application of the method and taking of shortcuts which compromise research quality. This way, systematic adherence to scientific procedures and quality guidelines may be facilitated. 
Thirdly, the scientific application of the focus group method is essential for quality reasons and must be emphasised and practised accordingly. A dire need for the regulatory enforcement of the scientific application of the focus group method has become an imperative for the local marketing research industry.

Fourthly, the fundamental need for scientific guidelines on focus group practice in South Africa must be satisfied through adherence to the quality considerations and guidelines provided in this section, as major quality pitfalls are highlighted for mitigation in real practice. Ensuring scientific quality in focus group research is a shared responsibility of all the participants who should make informed contributions within the focus group process. The way in which focus group research is conducted ultimately determines the quality of the research findings, and thus there may be no second chance to adherence to scientific research guidelines for quality reasons.

Fifthly, determining the correct budget size for a focus group project requires involvement and expertise of both stakeholder parties. An adequate budget is important for the efficient execution of the research project and may promote adherence to quality control procedures. Attempting to contain a project within a limited budget may lead to the taking of shortcuts by omitting certain procedures and overlooking some quality controls in order to complete the project within the limited budget available. The result may be a research quality trade-off.

Sixthly, research suppliers who ought to be equipped with technical know-how and experience on similar projects must assume the responsibility of technically assessing the adequacy of the final research budget, which should be flexible. An expert on focus group projects ought to have knowledge of the quality challenges that must be planned for fiscally, when budgets are set. Failure to incorporate unforeseen impediments to research quality in the budgets can be a major research quality compromise.

Seventhly, the correct size of the budget facilitates efficient execution of the project, and thus research quality may be attained, while project failure is generally attributed to inadequate budget sizes.

Eighthly, scientific focus group research practice ought to be the rule rather than the exception, as evidence of malpractices has been cited as contributing to poor quality research findings. Participants of integrity are becoming few, therefore effective strategies must be formulated to secure the efficient use of qualified participants required on focus group projects.

Lastly, as an imperative, the development of expertise for the execution of guidelines provided hereto must ensure quality in focus group practice and guide the interested groups into being able to tell good from bad focus group practice from an informed point of view.

\section{CONCLUSIONS AND RECOMMENDATIONS FOR FURTHER RESEARCH}

The ultimate role of marketing research including focus groups is to provide market information which is used as scientific evidence and that would assist with the marketing decision-making processes of organisations (Maritz, 2012, p. 12).

In the execution of the research task, rigorous adherence to methodological and other quality control measures, however, ought to be exercised in order to attain optimum quality of focus group research information. Enhancing production of high quality research is an imperative in South Africa, if the accuracy of marketing decisions of business organisations is to be improved within the local industry practice of focus groups.

Consequently, to assist in the identification of rigorous quality control measures, an overall comparative analysis of perceptions of research suppliers and users with regard to the quality challenges experienced across the focus group research process were examined in this study. The findings revealed numerous instances of similarities between research suppliers and users regarding their views on focus group research and the quality challenges thereof. In most of the cases measured, both groups either agreed or disagreed together, a trend that was confirmed through the significance of associations between the two groups. Following the research findings, a number of management guidelines were developed that will assist both research users as well as research suppliers in improving the standard of focus group research in South Africa. 
It is now recommended that a further research study ought to be conducted in order to assess the adoption and execution of the management guidelines within the marketing research industry so that recommendations may be made to address any anomalies identified. The objective would be to enforce adherence to scientific research practice and promote a more efficient and organised approach to focus group research in South Africa.

Furthermore, an investigation into the extent to which the South African marketing research industry may be conducive to scientific focus group research and promotion of best practice in this regard, can also be viewed as an urgent imperative. Given the evidence of research malpractices highlighted in the article, some orchestrated deliberately or some out of ignorance of research science, research to inform redress interventions on the environmental factors will be necessary. Besides, focus groups share the same environmental space as the other research methods, qualitative or quantitative. The malpractices in any of these methods ought to be investigated and mitigated if a conducive, scientific research environment is to be achieved in South Africa.

To close: This study, although limited in scope succeeded in establishing a set of management guidelines that could assist in enhancing research quality control across the focus group research process. At the same time and in the pursuit for best practice, the application of these management guidelines may mitigate the challenges that compromise the research quality of focus group research within the South African research environment.

Busani Dube is a Senior Lecturer in the Department of Marketing Management at the University of Johannesburg. $\mathrm{He}$ holds a PhD degree (Marketing Management) from the University of Johannesburg.

Mornay Roberts-Lombard is a Full Professor and Deputy Head of the Department of Marketing Management at the University of Johannesburg. He holds a PhD degree (Marketing Management) from the North-West University, has published numerous articles in scholarly journals and has delivered papers at local and international conferences. His areas of expertise are relationship marketing, services marketing and customer engagement. Email: mornayrl@uj.ac.za

Estelle van Tonder is an Associate Professor in the Program of Marketing at the North-West University and holds a DCom degree (Marketing Management) from the University of Pretoria. She was formerly the Head of Department in the School of Commerce at Milpark Education and prior to her position at Milpark Education, a senior lecturer in the Department of Marketing Management at the University of Johannesburg. Prof Van Tonder is a passionate researcher focusing on topics related to strategic marketing, services marketing and customer relationship management. She has published numerous articles in scholarly journals and has delivered papers at local and international conferences. Email: 25621610@nwu.ac.za (corresponding author)

\section{REFERENCES}

1. Aaker, D. A., Kumar, V. \& Day, G. S. (2004). Marketing research. 8th ed. New Jersey: John Wiley and Sons Inc.

2. Anthony, E. K. \& Austin, M. J. (2008). The role of intermediary organisation in promoting research in schools of social work: the case of the Bay area social services consortium. Social Work Research, 32 (4), 287-293.

3. Ashton, R. (2009). Using the research and development in organisations model to improve transition to high school. Education Psychology in Practice, 25 (3), 221-232.

4. Baruah, J. \& Paulus, P. B. (2009). Enhancing group creativity: the search for synergy. Research on Managing Groups and Teams, 12, 29-56.

5. Bryman, A. \& Belle, E. (2007). Business research methods. 2nd ed. Oxford: Oxford University Press.

6. Burns, A. C. \& Bush, R. F. (2014). Marketing research. 7th ed. New Jersey: Prentice Hall.

7. Cleveland, M. \& Delorie, J. (2010). Overview of African research industry. Retrieved from http://evolutionafrica.com/wp-content/uploads/2010/10/ESOMAR-Global-Market-Research-2010-AfricaHighlights.pdf 
8. DeRosia, E. D. \& Christensen, G. L. (2009). Blind insights: a new technique for testing a priori hypotheses with qualitative methods. Qualitative Market Research: An International Journal, 12 (1), 1535.

9. Ervin, N. E. \& Cowell, J. M. (2004). Integrating research into teaching public health nursing. Public Health Nursing, 21(2), 183-190. 342.

10. ESOMAR. (2014). Global market research 2014. An ESOMAR industry report. Retrieved from http://www.esomar.org/uploads/industry/reports/global-market-research-2014/ESOMAR-GMR2014Preview.pdf

11. Falala, S. (2003). Market research: a growth industry:2-4. Retrieved from http:/www.bizcommunity.com/article/196/19/2879.html.

12. Famili, A. (2005). Editorial. Intelligent Data Analysis-An International Journal, 9(5), 417-418.

13. Green, J. (2003). Marketing and research for Africa: online industry resource:2-4. Retrieved from http:/www.bizcommunity.com/article/196/19/2332.html.

14. Green, J. \& Green, M. (2005). Your qualitative recruiting: fact, fantasy or fiction:1-9. Retrieved from http:/www.marfa.co.za/papers-select.php?id=19.

15. Hartman, J. (2004). Using focus groups to conduct business communication research. Journal of Business Communication, 41(4), 402-410.

16. Keegan, S. (2009). Practitioner perspective: “emergent inquiry"; a practitioner's reflections on the development of qualitative research. Qualitative Market Research: An International Journal, 12 (2), 234248 .

17. Kent, R. (2007). Marketing research: approaches, methods and applications in Europe. London: Thomson.

18. Kolb, C. (2005). Ask Africa: Research methods in question. :2-4. Retrieved from: http:/www.bizcommunity.com/article/196/19/6697.html.

19. Kress, V. E. \& Shoffner, M. F. (2007). Focus groups: a practical and applied research approach for counsellors. Journal of Counselling and Development, 85(2), 189-195.

20. Malhotra, N.K. (2010). Marketing research: an applied orientation. 6th ed. New Jersey: Prentice Hall Inc.

21. Maree, D. \& Wagner, C. (2007). Teaching research methodology: implications for psychology on the road ahead. South African Journal of Psychology, 37(1), 121-134.

22. Martin, S. (Ed.). (2006). Creativity through consumer research:2-4. Retrieved from http:/www.bizcommunity.com/article/196/19/11542.html.

23. Maritz, V. (2012). Strategic use of data visialisation and storytelling in marketing research firms. (Masters thesis, University of Johannesburg, South Africa).

24. Mrosovsky, N. (2006). The marginalisation of methods. Bioscienc,. 56(10), 790-791.

25. Pallant, J. (2010). SPSS survival manual: A step by step guide to data analysis using SPSS. 4th ed. Berkshire: McGraw-Hill Education.

26. Prakash, V. (2013). A study on usage of geospatial technologies in power utility. International Journal of Research in Commerce, IT and Management, 3(9), 71-76.

27. Raby, R. (2010). Public selves, inequality, and interruptions: the creation of meaning in focus groups with teens. International Journal of Qualitative Methods, 9(1), 1-15.

28. Ratcliff, D. (2008). Qualitative data analysis and the transforming moment. Transformation 25. Paternoster periodicals, 2 \& 3 April \& July, 116-133.

29. SAMRA. (2009). History: what is SAMRA? : 1-3. Retrieved from http:/www.SAMRA.co.za/index.php?page=about@ show=history.

30. SAMRA. (2010). SAMRA Yearbook 2010. 19th ed. Southern African Marketing Research Association, Randburg.

31. Segal, M. N., Hershberger, E. K. \& Osmonbekov, T. (2009). Rethinking assessment of marketing research skills and knowledge : a new approach. Qualitative Market Research: An International Journal, 12 (1), 7082.

32. Simon, C. M. \& Mosavel, M. (2008). Ethical design and conduct of focus groups in bioethics research. Empirical Methods for Bioethics: A primer Advances in Bioethics, 11, 63-81.

33. Smith, D. (2003). Research is now a transformation agent: 3-4. Retrieved from http:/www.bizcommunity.com/article/196/19/3436.html. 
34. Stavros, C. \& Westberg, K. (2009). Using triangulation and multiple case studies to advance relationship marketing theory. Qualitative Market Research: An International Journal, 12 (3), 307-320.

35. Stokes, D. \& Bergin, R. (2006). Methodology or "methodolatry"?: an evaluation of focus groups and depth interviews. Qualitative Market Research: An International Journal, 9(1), 26-37. 354.

36. University of Wisconsin-Madison. (1999). Focus groups. When and why to use. Retrieved from http://www.virginia.edu/processsimplification/resources/WiscFocusGroups.pdf

37. Victor, N. (2009). Interview: Overview of the South African marketing research industry (describe). June $11 @ 10$ am). Available on tape.

38. Vorster, L. (2008). Chairman's Address. SAMRA Yearbook 2008. Southern African Marketing Research Association.

39. Welman, C., Kruger, F. \& Mitchell, B. (2005). Research methodology. 3rd ed. Cape Town: Oxford University Press Southern Africa.

40. Zikmund, W. G. \& Babin, B. J. (2013). Essentials of marketing research. 5th ed. Louisiana: South Western. 
NOTES 